\title{
Studies on conventional cutting of intermetallic nickel and titanium aluminides
}

\author{
E Uhlmann and S Herter* \\ Institute for Machine Tools and Factory Management, Technical University Berlin, Berlin, Germany
}

The manuscript was received on 4 May 2005 and was accepted after revision for publication on 19 April 2006.

DOI: $10.1243 / 09544054 J E M 377$

\begin{abstract}
Owing to the high percentage of covalent bonds, intermetallic nickel and titanium aluminides have specific physical and chemical characteristics that predestine them for components under high thermal and mechanical load. However, the relatively low ductility and thermal conductivity at room temperature, linked to high tensile strength, impede the machining with geometrically defined cutting edges in series production.

The conventional machining process is characterized by microcrack formation at the component surface. One possible way is to warm up the intermetallic alloys locally above the quasi-brittle-ductile transition temperature by the interaction of the workpiece material and the tool.

The subjects of investigation were the influences of feed rate and cutting speed on the tool-face temperature and cutting force as well as on the chip formation and fringe-area formation during longitudinal cylindrical turning. The experiments were carried out with intermetallic nickel and titanium aluminides in an as-cast and extruded state. The goal was to elaborate the technological basic knowledge for a damage-minimized and productive machining of intermetallic aluminides with geometrically defined cutting edges.
\end{abstract}

Keywords: turning, nickel and titanium aluminides

\section{INTRODUCTION}

Owing to the high percentage of covalent bonds, intermetallic aluminides have specific physical and chemical characteristics that predestine them for components in automotive engines, turbines, and other components under high thermal and mechanical load.

Intermetallic nickel aluminides (NiAl) offer significant advantages in contrast to many conventional metallic heat-resistant materials, including low density, high melting point, good corrosion resistance, high degree of structural stability, high tensile strength in a wide range of temperature, metal-like properties above a modest ductile-brittle transition temperature of about $400^{\circ} \mathrm{C}$, and low

*Corresponding author: Institute for Machine Tools and Factory Management, Technical University Berlin, Berlin, Germany.email: herter@iwf.tu-berlin.de raw material costs. Strong bonding between aluminium and nickel, resistant to high temperatures, can provide high strength at elevated temperatures, the specific strength of intermetallics thus being competitive with superalloys and ceramics. These attractive properties allow the application of the material in high-temperature components such as potential structural materials in the aerospace industry, hardware for hot sections of gas turbine engines or buried interconnections in electronic components. Besides these outstanding characteristics, however, poor toughness, and damage tolerance at room temperature as well as inadequate strength and creep resistance at high temperature are two principal restrictions. In terms of ductility, intermetallic nickel aluminides are between metals and ceramics. In this connection, the material's low ductility causes problems in the machining of semi-finished or finished products. 

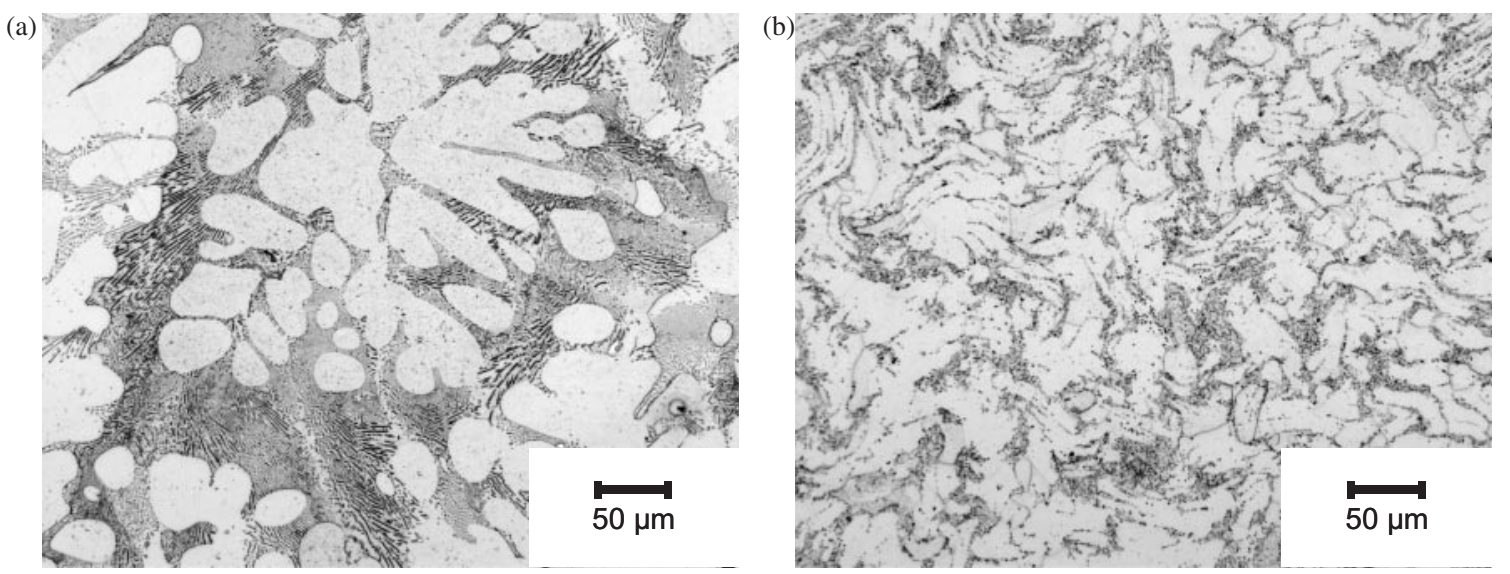

Fig. 1 Light microscopic images of the micro structures of $\mathrm{NiAl}-\mathrm{Hf}_{0,6} \mathrm{~B}_{1,2}$, (a) in the as-cast state, and (b) subsequently in the hot extruded state

NiAl offers six key advantages $[\mathbf{1}, \mathbf{2}]$ :

(a) density of $5.95 \mathrm{~g} / \mathrm{cm}^{3}$, which is approximately two-thirds of state-of-the-art nickel-based superalloys;

(b) thermal conductivity, which is $4-8$ times higher than those of nickel-based superalloys (dependent on composition and temperature);

(c) excellent oxidation resistance;

(d) $\mathrm{CsCl}$ crystal structure and small slip vectors for potentially easier plastic deformation compared to many other intermetallic compounds;

(e) lower ductile-brittle transition temperature, relative to other intermetallics;

(f) high melting temperature $\left(1682^{\circ} \mathrm{C}\right)$, which is approximately $320^{\circ} \mathrm{C}$ higher than the nickelbased superalloys [2]. The thermal expansion characteristics are similar to those of the nickel-based superalloys.

The $\gamma$-TiAl-based alloys have a higher oxidation resistance, a substantially smaller addiction to hydrogen embrittlement, higher creep strength, and a higher E-module compared to conventional Tibased alloys. A further advantage is the significantly lower addiction to Ti-fire. Furthermore, $\gamma$-TiAlbased alloys have a 50 per cent lower density than Ni-based superalloys [3-5].

Because of their advantageous mechanical properties at high temperatures of up to $750^{\circ} \mathrm{C}$ and sufficient damage tolerance at low temperatures, TiAl-based alloys are suitable for rotating and oscillating engine parts. However, owing to relatively low ductility and thermal conductivity at room temperature linked to high tensile strength, these materials are difficult to machine with geometrically defined cutting edges. The development of a reliable and cost-efficient machining technology plays a key role in the industrial application of TiAl-based alloys [6-8].

\section{STRUCTURE OF THE INVESTIGATED ALUMINIDES}

\subsection{Nickel aluminides}

The microstructure of hypoeutectic die-cast NiAl- $-\mathrm{Hf}_{0,6} \mathrm{~B}_{1,2}$ alloys shows dendritic NiAl primary crystals with an average main diameter of $d=$ $50 \mu \mathrm{m}$, which are embedded into networks of a fine fibrous eutectic with a volume ratio of approximately 25 per cent (Fig. 1(a)). Within the NiAl primary crystals, $\mathrm{HfB}_{2}$ particles can be found in a very low concentration of $\ll 1$ vol per cent that deposited as a result of solubility.

The hot extrusion of NiAl- $\mathrm{Hf}_{0,6} \mathrm{~B}_{1,2}$ cast alloys completely dissolves the eutectic networks and arranges the eutectic and the primary NiAl crystals into columnar cells with an average diameter of approximately $20 \mu \mathrm{m}$ lengthwise to the direction of extrusion (Fig. 1(b)). The single cells consist of subgrains, which mostly have smallangle grain boundaries. Subgrains of NiAl-based alloys in the hot extruded state were proven by TEM $[\mathbf{9}, \mathbf{1 0}]$.

\subsection{Titanium aluminides}

The microstructural parameters of TiAl-based alloys are determined crucially by the chemical composition and the process parameters of the production and the further processing of semi-finished products and components. The characteristic structures vary in terms of phase morphology (lamellar, duplex, near- $\gamma$, or globular/cellular), the grain and cell size of the structure and of the volume fraction of the coexisting phases $\alpha_{2}\left(\mathrm{Ti}_{3} \mathrm{Al}\right)$ and $\gamma$ (TiAl). The treatment parameters for the specific formation of the desired structures are performance-related.

The morphology of the as-cast structure is influenced substantially by the speed of solidification. 

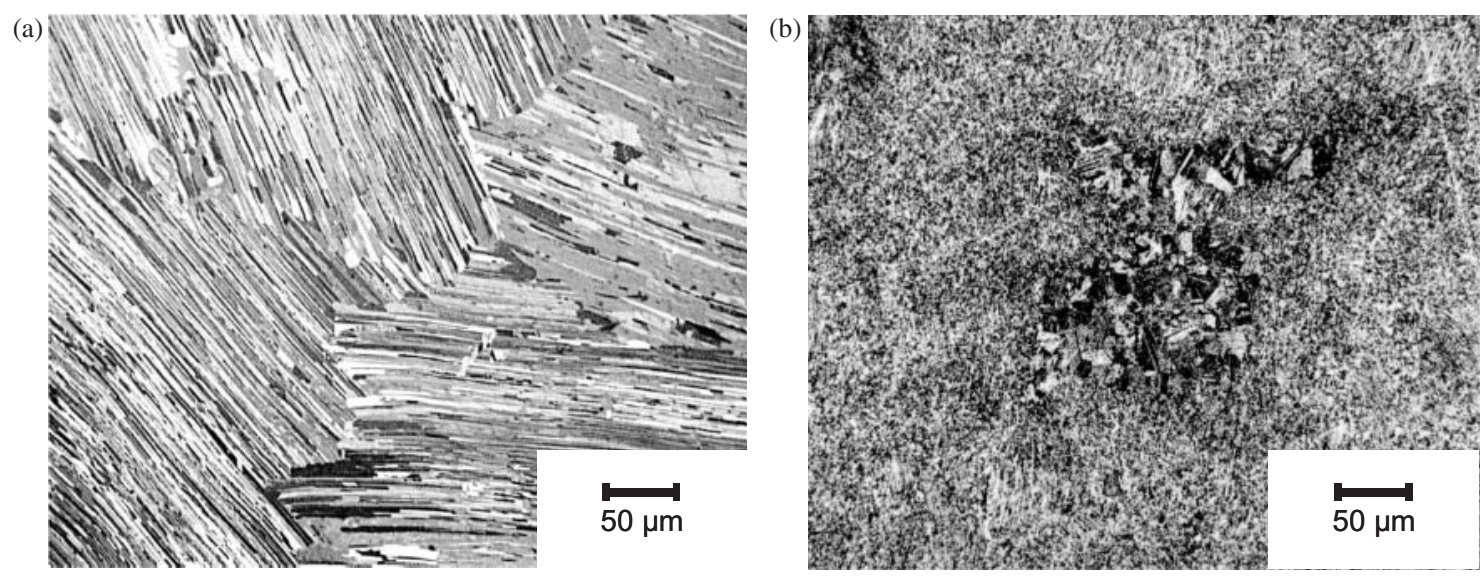

Fig. 2 Triple point of lamellar grains, (a) in the lamellar solidification structure, and (b) in the, fine-grained near- $\gamma$-structure after hot extrusion with $\mathrm{A}_{0} / \mathrm{A}=14: 1$ with island of coarse $\gamma$-grains

The shape of the solidification front in the crystallization state depends on the cooling rate. Figure 2(a) shows the lamellar structure of the Ti-46.8Al-1Mo$0.2 \mathrm{Si}$ alloy. The lamellar grains, whose diameter can be between $300 \mu \mathrm{m}$ and $600 \mu \mathrm{m}$, sometimes up to $1200 \mu \mathrm{m}$, form toothed boundary layers. This interconnection of adjacent grains has a positive effect on the creep properties [11].

The lamellar cells are intercellulary, interstratified with primarily solidified single-phase $\gamma$-areas that have grain sizes of less than $100 \mu \mathrm{m}$. The volume content of the $\alpha_{2}$-phase is approximately 15-20 vol per cent. The average width of the $\alpha_{2}$-lamellae was determined as $200 \mathrm{~nm}$ by TEM-investigations.

Through the hot extrusion of the TiAl-based alloys in the two-phase temperature field $\alpha+\gamma$, the lamellar cast structure is transformed into a relatively homogeneous recrystallization structure of grain sizes of less than $4 \mu \mathrm{m}$, owing to the dynamic recrystallization. The structure diagonal to the direction of extrusion shown in Fig. 2(b) of the alloy extruded with the diameter ratio of $\mathrm{A}_{0} / \mathrm{A}=14: 1$ has a characteristic line pattern parallel to the direction of extrusion. It is interstratified with dispersed $\alpha_{2}$-particles and insular areas of coarse $\gamma$-grains stretched in the direction of extrusion. The $\alpha_{2}$-phases are mainly in the grain boundaries, the triple points thus impeding the thermally or thermomechanically induced grain growth during extrusion. This structure, which is typical for as-cast TiAl-based alloys extruded in the $\alpha+\gamma$-field, corresponds to the near- $\gamma$-structure. In structural ranges with a low-volume fraction of the $\alpha_{2}$-phase the average grain size of the $\gamma$-grains of $10-30 \mu \mathrm{m}$ is clearly larger. These zones have a diameter of $60-150 \mu \mathrm{m}$. The heterogeneous distribution of the $\alpha_{2}$-phase in the structure of the extruded alloy can be traced back to microsegregations in the casting material.

\section{EXPERIMENTS}

The turning tests were carried out on a TNS 30 CNC inclined bed-turning lathe by the Traub Company, Germany. The design of the machine tool allows chucking works of a diameter of up to $D_{\mathrm{D}}=$ $140 \mathrm{~mm}$ at a turning length of $L_{\mathrm{D}}=220 \mathrm{~mm}$.

Cemented carbides of ISO specification K10 and polycrystalline cubic boron nitride (cBN DBC 80) were used for the cutting tests. The geometry of the cutting inserts was taken from the ISO code SPUN 12(09)0308. A tool holder of the ISO specification CSBPL was used. This results in a rake angle of $\gamma_{\mathrm{o}}=5^{\circ}$ and a clearance angle of $\alpha_{\mathrm{o}}=6^{\circ}$. The setting angle was $\kappa_{\mathrm{r}}=75^{\circ}$. The investigations were carried out in the dry cutting mode. The cutting speed varied between $v_{\mathrm{c}}=10 \mathrm{~m} / \mathrm{min}$ and $v_{\mathrm{c}}=150 \mathrm{~m} / \mathrm{min}$ for cemented carbides and up to $v_{\mathrm{c}}=300 \mathrm{~m} / \mathrm{min}$ for cBN inserts. The influence of the structure and the cutting parameters on the cutting process during the turning of intermetallic nickel and titanium aluminides will be investigated in the following.

To determine the real temperatures occurring during the cutting process in the relevant shear zones is very complicated, because no direct access is possible. Determining the temperature with thermal elements integrated in the workpiece or the tool provides only integral average values. Infrared thermography, alternatively, represents a possibility to detect locally temperatures with high resolution.

In order to enable early indications of the temperatures occurring during the turning of intermetallic aluminides, the rake-face temperatures were detected first. Therefore, it was necessary to interrupt the cutting process for a short time in order to take a picture. The JADE II MwIR IR thermography system by the Infratec GmbH, Dresden, served as 


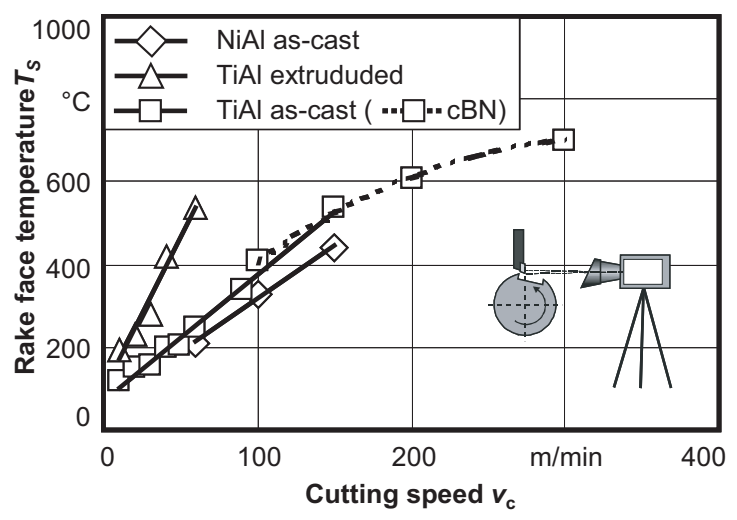

\begin{tabular}{|c|c|c|c|c|c|}
\hline \multirow{7}{*}{\multicolumn{3}{|c|}{$\begin{array}{l}\text { Work piece material: } \\
\text { Structure: } \\
\text { Cutting tool: } \\
\text { Cutting speed: } \\
\text { Feed: } \\
\text { Cutting depth: } \\
\text { Working geometry: }\end{array}$}} & \multicolumn{3}{|c|}{$\mathrm{NiAl} \mathrm{Ti}$} \\
\hline & & & \multicolumn{3}{|c|}{ as-cast, extruded } \\
\hline & & & \multicolumn{3}{|c|}{ carbide, cBN } \\
\hline & & & \multicolumn{3}{|c|}{$10 \mathrm{~m} / \mathrm{min}-300 \mathrm{~m} / \mathrm{min}$} \\
\hline & & & \multicolumn{3}{|c|}{0.02 and $0.05 \mathrm{~mm} / \mathrm{rev}$} \\
\hline & & & \multirow{2}{*}{\multicolumn{3}{|c|}{0.3 and $0.5 \mathrm{~mm}$}} \\
\hline & & & & & \\
\hline$\alpha_{0}$ & $\gamma_{0}$ & $\lambda_{s}$ & $\varepsilon_{r}$ & $\kappa_{\mathrm{r}}$ & $r_{\varepsilon}$ \\
\hline $6^{\circ}$ & $5^{\circ}$ & $0^{\circ}$ & $90^{\circ}$ & $75^{\circ}$ & $0.8 \mathrm{~mm}$ \\
\hline
\end{tabular}

Fig. 3 Tool temperatures depending on the workpiece material and cutting speed

a measuring system working in real time. The advantage of this camera system was the possibility of external triggering. A groove was worked into the respective workpieces with a constant engagement/off-engagement ratio of 90 per cent. With the help of an external trigger box with an inductive signal transmitter and temporal variable output signal developed at the IWF, the timing for taking the picture was optimized so that pictures could be taken of the rake face without the flowing chip covering the rake face of the tool.

In this procedure, note that the cutting edge cools down during the off-engagement time. The detected temperatures are therefore below the actual rakeface temperatures. They show that the adjustment of the cutting parameters (particularly of the cutting speed) may lead to temperatures in the chip formation zone that make ductile cutting possible.

Figure 3 shows the tool temperatures depending on the cutting speed for turning of as-cast NiAl as well as extruded and as-cast TiAl. The temperatures of the face during the turning of both $\gamma$-TiAl workpiece materials rise linearly with the cutting speed. The temperatures of the rake face determined during the turning of the extruded TiAl are at each cutting speed clearly above the temperatures detected during the turning of as-cast TiAl. The temperature of $T_{\mathrm{S}}=250^{\circ} \mathrm{C}$ for as-cast material and $T_{\mathrm{S}}=540^{\circ} \mathrm{C}$ for extruded TiAl was measured at $v_{\mathrm{c}}=60 \mathrm{~m} / \mathrm{min}$. A further increase of the cutting speed to $v_{\mathrm{c}}=$ $150 \mathrm{~m} / \mathrm{min}$ led to temperatures of $T_{\mathrm{S}}=535^{\circ} \mathrm{C}$ also in the case of as-cast TiAl. The temperatures verified during the turning of the as-cast NiAl alloys are always approximately 15 per cent lower than those of as-cast TiAl. Note that the brittle-ductile transition temperature (BDTT) in the case of $\mathrm{NiAl}$ at approximately $400^{\circ} \mathrm{C}$ is also clearly lower than that of TiAl at approximately $650^{\circ} \mathrm{C}$.

Owing to the relatively low thermal conductivity of tungsten carbides, the thermal stress of the indexable inserts is very much localized. High thermal stress leads to the failure of the indexable inserts of tungsten carbide after a few mm of feed. Because of these observed tendencies, cutting tests were carried out on as-cast TiAl in a continuous section with polycrystalline cubical boron nitride (cBN), which clearly has a higher heat resistance. Consequently, the feed was reduced to $f=0.02 \mathrm{~mm}$ and the depth of cut to $a_{\mathrm{p}}=0.3 \mathrm{~mm}$ in order to protect the cutting edge from high mechanical loads during the cutting process. The increase of the cutting speed to $v_{\mathrm{c}}=300 \mathrm{~m} / \mathrm{min}$ led to an increase of the face temperature to $T_{\mathrm{S}}=700^{\circ} \mathrm{C}$.

Through the adaptation of the cutting speed, temperatures were generated in the active zone for both materials that were above the BDTT. In order to verify the effects of the high cutting temperatures on the experiment result, SEM images were taken of the formed chips, subsurfaces, and selected chip roots. The chip roots were formed with a quick-stop device developed at the Institute for Machine Tools and Factory Management (IWF) that made it possible to obtain a chip root at real process conditions.

With an increasing cutting speed the NiAl chips showed a slightly more regular segmentation. At low cutting speeds cracks were detected at the underside of the chip that did not occur at $v_{\mathrm{c}}=$ $150 \mathrm{~m} / \mathrm{min}$. Also, the transverse grindings showed that the chip structure is deformed to a greater extent if the cutting speed increases. This suggests an increase of friction at the face. This assumption is endorsed by the detected face temperatures.

Figure 4 shows the surfaces and fringe areas of ascast NiAl probes after turning with $v_{\mathrm{c}}=60 \mathrm{~m} / \mathrm{min}$ and $v_{\mathrm{c}}=150 \mathrm{~m} / \mathrm{min}$. With an increasing cutting speed, much smaller defects occur in the subsurface. While the subsurface is full of cracks at $v_{\mathrm{c}}=$ $60 \mathrm{~m} / \mathrm{min}$ which stretch from the surface $50 \mu \mathrm{m}$ into the base material, at $v_{\mathrm{c}}=150 \mathrm{~m} / \mathrm{min}$, it is badly deformed in the direction of cut. These deformations reach a depth of $30 \mu \mathrm{m}$. Here, cracks can also be detected in the subsurface that reach to a depth of only $10 \mu \mathrm{m}$ if clearly stretching into the direction of cut. Investigations into the created chip 

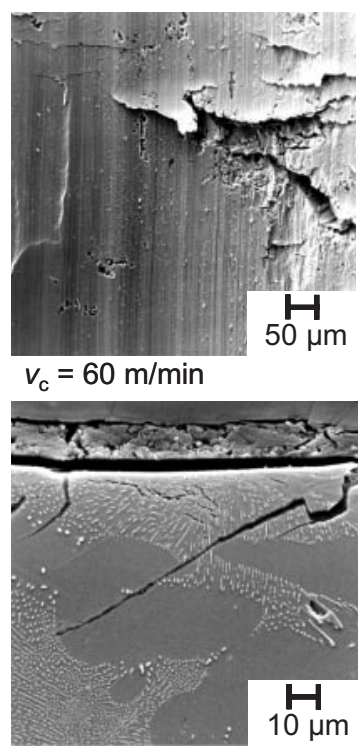

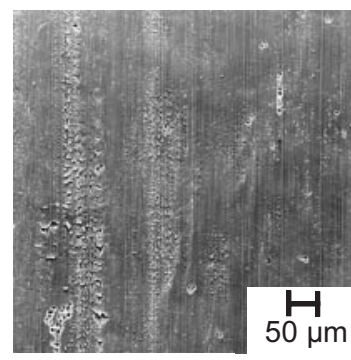

$v_{\mathrm{c}}=150 \mathrm{~m} / \mathrm{min}$

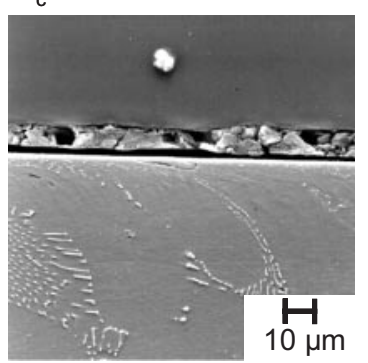

Work piece material: $\quad \mathrm{NiAl}$

Structure:

as-cast

carbide

60 to $150 \mathrm{~m} / \mathrm{min}$

$0.05 \mathrm{~mm} / \mathrm{rev}$

$0.25 \mathrm{~mm}$

Cutting depth:

Working geometry:

\begin{tabular}{|c|c|c|c|c|c|}
$\alpha_{0}$ & $\gamma_{0}$ & $\lambda_{\mathrm{S}}$ & $\varepsilon_{r}$ & $\kappa_{\mathrm{r}}$ & $r_{\varepsilon}$ \\
\hline- & - & $0^{\circ}$ & $90^{\circ}$ & $75^{\circ}$ & $0.8 \mathrm{~mm}$ \\
\hline
\end{tabular}

Fig. 4 Surfaces and fringe areas of as-cast NiAl after turning

roots showed that the cracks start from the cut edge, i.e. from the area of the biggest chipping thickness.

At all cutting speeds, bead-like cavities could be detected on the surfaces that presumably occur as a result of hard material particles breaking off. These cavities also occur during the turning of extruded alloys. Unlike the as-cast modification, the deformation of the subsurface in the direction of cut appears to be more pronounced in the case of lower cutting speeds. Nonetheless, at $v_{\mathrm{c}}=30 \mathrm{~m} / \mathrm{min}$, more cracks occur on the surface that mostly run diagonally to the direction of cut. At the cutting speeds investigated, there are also badly deformed cracks to a depth of approximately $20 \mu \mathrm{m}$ into the base material. The shape of the cracks suggests that for both structure states, the crack formation and deformation of the subsurface occurred successively. This assumption is endorsed by the strong break-offs detected at the cutting edge and the base material of the chip roots.

These strong break-offs could not be observed during the machining of more ductile TiAl-alloys. The chips showed a significant improvement of cohesion with an increasing cutting speed (Fig. 5). While the single-chip segments are almost completely separated at $v_{\mathrm{c}}=60 \mathrm{~m} / \mathrm{min}$, chips formed at $v_{\mathrm{c}}=300 \mathrm{~m} / \mathrm{min}$ show a wide zone of plastic deformation at the underside of the chip. In contrast to the short discontinuous chips at low cutting speed, long blue-coloured chips are formed here. This can be attributed to the detected high temperatures at the secondary shear zone. The cohesion of the chips during the turning of the extruded alloy is always slightly higher. This is due to the more homogeneous and fine-grained structure of extruded TiAl.
The cutting speed has a crucial influence on the formation of the surface and the subsurface which in turn is considerably affected by the lower temperatures stated at low cutting speeds. While the average surface roughness decreases with growing cutting speeds to $R_{\mathrm{z}}=1.85 \mu \mathrm{m}$ at $v_{\mathrm{c}}=$ $10 \mathrm{~m} / \mathrm{min}$ and to $R_{\mathrm{z}}=1.2 \mu \mathrm{m}$ at $v_{\mathrm{c}}=300 \mathrm{~m} / \mathrm{min}$ in the case of both materials, many small cracks and break-offs occur on the surface of the as-cast alloy at low cutting speeds up to $v_{\mathrm{c}}=60 \mathrm{~m} / \mathrm{min}$ while the surface of the material turned with $v_{\mathrm{c}}=$ $300 \mathrm{~m} / \mathrm{min}$ is absolutely free of such defects.

The deformation of the workpiece subsurface described many times in the literature could be proven for both structure states $[\mathbf{8}, \mathbf{9}]$. The SEM images show that there are no cracks and chippings in the fringe zone (Fig. 6) of turned extruded and as-cast TiAl also.

The extent of the deformation seems to depend on the angle of the lamellae in the case of the as-cast alloy. In the case of the lamellae being parallel to the formed surface, only a very slight deformation could be observed. If, in turn, the lamellar grains are vertical to the surface, deformations reach depths of more than $20 \mu \mathrm{m}$ independently of the cutting speed. There are also deformations in the subsurface in the direction of cut in the case of extruded workpieces. In images taken of the etched subsurfaces of both workpiece materials, a so-called 'white layer' could be observed, similar to that observed during machining of hardened steel. The depth of these zones of increased strength which are less affected by subsequent etching reaches $10 \mu \mathrm{m}$. Figure 7 displays the formation of continuous chips while turning as-cast TiAl with $\mathrm{cBN}$ at $v_{\mathrm{c}}=$ $300 \mathrm{~m} / \mathrm{min}$. 

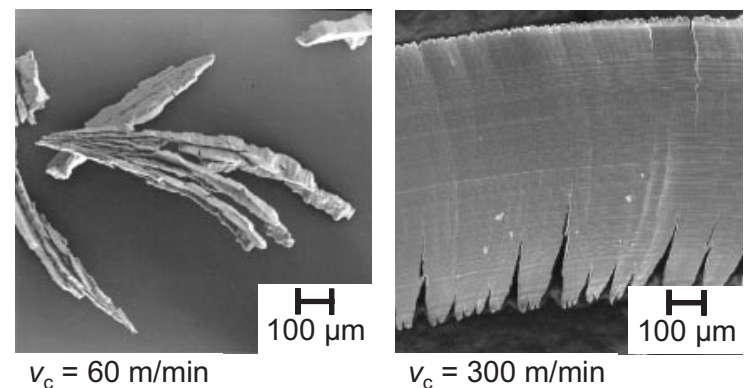

\begin{tabular}{|c|c|c|c|c|c|}
\hline \multicolumn{3}{|c|}{ Work piece material: } & \multicolumn{3}{|l|}{ TiAl } \\
\hline \multicolumn{3}{|c|}{ Structure: } & \multicolumn{3}{|c|}{ as-cast } \\
\hline \multicolumn{3}{|c|}{ Cutting tool: } & \multicolumn{3}{|c|}{ carbide, cBN } \\
\hline \multicolumn{3}{|c|}{ Cutting speed: } & \multicolumn{3}{|c|}{60 and $300 \mathrm{~m} / \mathrm{min}$} \\
\hline \multicolumn{3}{|c|}{ Feed: } & \multicolumn{3}{|c|}{0.05 and $0.02 \mathrm{~mm} / \mathrm{rev}$} \\
\hline \multicolumn{3}{|c|}{ Cutting depth: } & \multicolumn{3}{|c|}{0.5 and $0.3 \mathrm{~mm}$} \\
\hline \multicolumn{6}{|c|}{ Working geometry: } \\
\hline $\mathrm{o}$ & 0 & s & $r$ & $\mathrm{r}$ & $r_{\varepsilon}$ \\
\hline - & - & $0^{\circ}$ & $90^{\circ}$ & $75^{\circ}$ & $0.8 \mathrm{~mm}$ \\
\hline
\end{tabular}
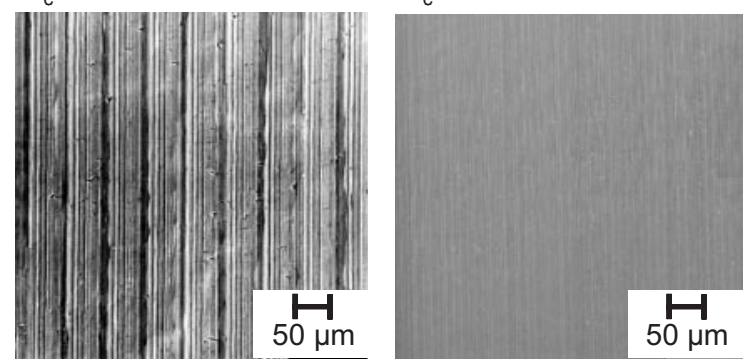

Fig. 5 Chips and surfaces of as-cast TiAl after turning

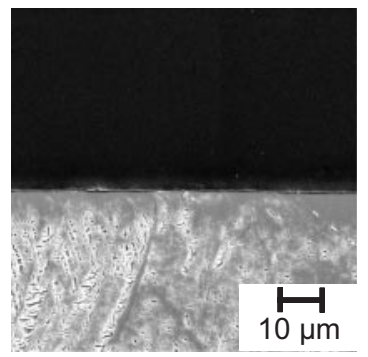

as-cast

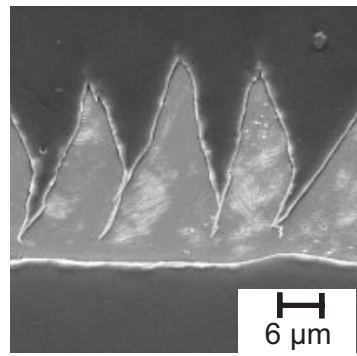

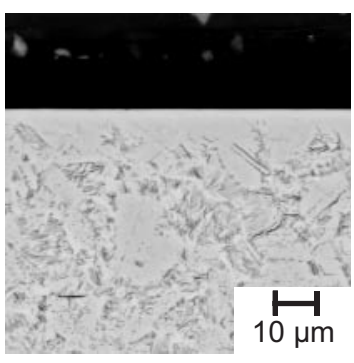

extruded

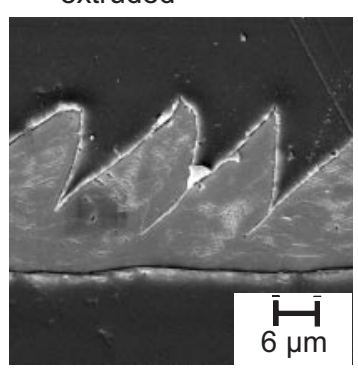

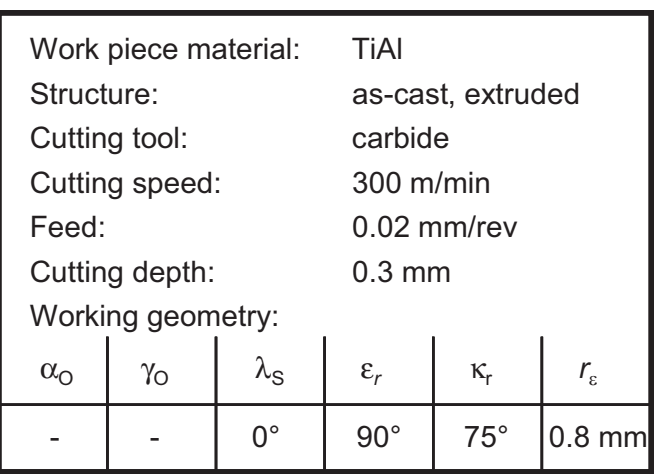

Fig. 6 Subsurfaces and chips after high-speed turning of TiAl

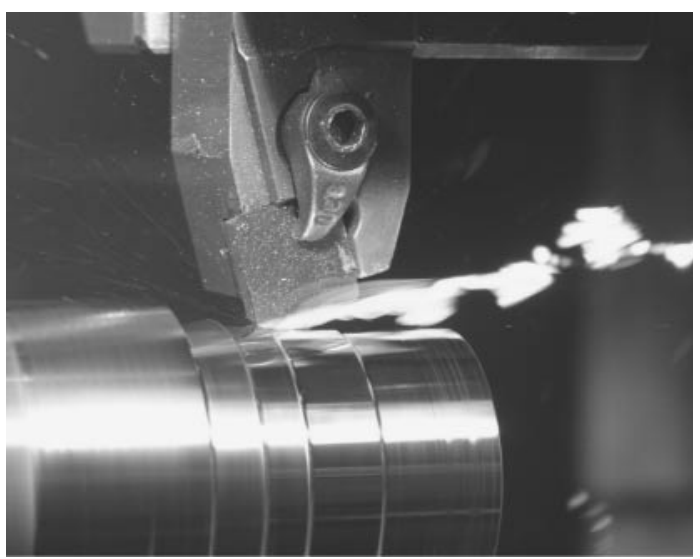

\begin{tabular}{|c|c|c|c|c|c|}
\hline \multirow{2}{*}{\multicolumn{3}{|c|}{ Work piece material: }} & \multicolumn{3}{|l|}{ TiAl } \\
\hline & & & \multicolumn{3}{|c|}{ as-cast } \\
\hline \multicolumn{3}{|c|}{ Cutting tool: } & \multicolumn{3}{|c|}{$\mathrm{cBN}$} \\
\hline \multicolumn{3}{|c|}{ Cutting speed: } & \multicolumn{3}{|c|}{$300 \mathrm{~m} / \mathrm{min}$} \\
\hline \multicolumn{3}{|c|}{ Feed: } & \multicolumn{3}{|c|}{$0.02 \mathrm{~mm} / \mathrm{rev}$} \\
\hline \multirow{2}{*}{\multicolumn{3}{|c|}{$\begin{array}{l}\text { Cutting depth: } \\
\text { Working geometry: }\end{array}$}} & \multicolumn{3}{|c|}{$0.3 \mathrm{~mm}$} \\
\hline & & & & & \\
\hline$\alpha_{0}$ & $\gamma_{0}$ & $\lambda_{\mathrm{S}}$ & $\varepsilon_{r}$ & $\kappa_{r}$ & $r_{\varepsilon}$ \\
\hline- & - & $0^{\circ}$ & $90^{\circ}$ & $75^{\circ}$ & $0.8 \mathrm{~mm}$ \\
\hline
\end{tabular}

Fig. 7 Turning of intermetallic TiAl at high cutting speed with cBN cutting tool 
In turning intermetallic TiAl with cemented carbides, the cutting speed is limited to $v_{\mathrm{c}}=$ $60 \mathrm{~m} / \mathrm{min}$. The high thermal and mechanical load led to an abrupt tool failure above this cutting speed. Therefore, different $\mathrm{cBN}$ grades and one PCD grade were investigated with respect to tool life and wear behaviour. The constitution of the $\mathrm{cBN}$ grades and the PCD is given in Table 1.

Turning tests at as-cast TiAl were carried out to assess the suitability of the different grades shown above. Two different cutting speeds, $v_{\mathrm{c}}=$ $100 \mathrm{~m} / \mathrm{min}$ and $v_{\mathrm{c}}=200 \mathrm{~m} / \mathrm{min}$, were chosen for the first tests. Figure 8 shows the results of the tool life tests. It can be seen clearly that the total tool life increases with decreasing grain size. The tool made of cBN $80 / 6$ only reaches a total tool life of $30 \mathrm{~s}$. In contrast, the finer grained grades withstand the tribological stress for about $180 \mathrm{~s}$. The content of cBN has no significant influence on the total tool life. Because of the relatively low temperatures while turning as-cast TiAl with a cutting speed of $v_{\mathrm{c}}=$ $100 \mathrm{~m} / \mathrm{min}$, the significant hardness of PCD is the reason for the relatively long total tool life of $210 \mathrm{~s}$.

With an increasing cutting speed of $v_{\mathrm{c}}=$ $200 \mathrm{~m} / \mathrm{min}$ associated with an increasing rake-face temperature, the total tool lives decrease significantly. The best total tool lives of $35 \mathrm{~s}$ were achieved with the cBN grade $65 / 2$. The larger grain size cBN tool $(80 / 6)$ only reaches a total tool life of $10 \mathrm{~s}$.

Table 1 Investigated grades of polycrystalline cubical boron nitride and diamond

\begin{tabular}{rlll}
\hline Material & \% cBN & Grain size $(\mu \mathrm{m})$ & Binder \\
\hline cBN 80/6 & 80 & 6 & TiAIN \\
cBN 90/2 & 90 & 2 & Co \\
cBN 65/2 & 65 & 2 & TiN \\
PCD 002 & - & 2 & Co \\
\hline
\end{tabular}

Machining of titanium containing materials with diamond and $\mathrm{cBN}$ is difficult because of critical temperatures. Temperatures above these critical values lead to processes of diffusion. By increasing the cutting speed to $v_{\mathrm{c}}=200 \mathrm{~m} / \mathrm{min}$ the total tool lives decrease to about $30 \mathrm{~s}$ for the fine-grained $\mathrm{cBN}$ tools and $20 \mathrm{~s}$ for the diamond tool. A reason for the lower total tool life of the diamond tool can be assumed to be the lower critical temperature of diamond compared to $\mathrm{cBN}$ when in contact with titanium. The high affinity between titanium and carbon and the metastable structure of diamond lead to added tribochemical reactions. Therefore the achievable total tool life of PCD cutting tools decreases drastically while turning TiAl with higher cutting speeds. It has to be remembered that the cutting conditions at the cutting edge deteriorate with increasing wear and the cutting temperature increases with growing friction. The brazed PCD tool tip breaks off totally after reaching a width of wear land of $V B=0.15 \mathrm{~mm}$.

\section{SUMMARY}

To summarize, the temperatures in the chip formation zone exceed the BDTT of both intermetallic materials. Cemented carbide tools showed a good potential for machining at low cutting speeds and therefore below the BDTT. Higher cutting speeds and higher temperatures are only possible with superhard cutting tool materials such as polycrystalline cubic boron nitride or diamond. Ceramic cutting materials are unable to withstand the high tribological stress during the turning of intermetallic nickel and titanium aluminides. In contrast to the extreme brittle NiAl material, a ductile mode-turning of brittle, intermetallic TiAl-alloys is actually possible using conventional technology. The cutting

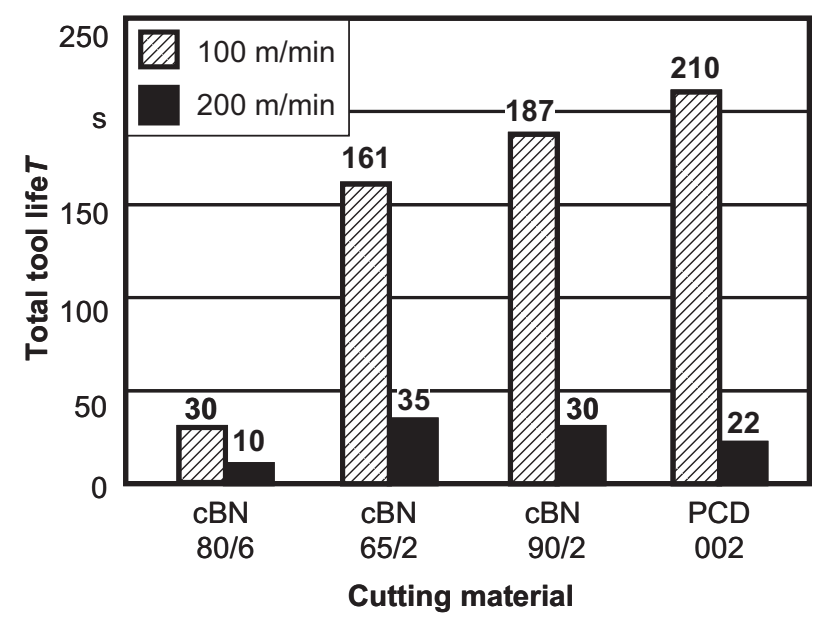

\begin{tabular}{|c|c|c|c|c|c|}
\hline \multirow{7}{*}{\multicolumn{3}{|c|}{$\begin{array}{l}\text { Work piece material: } \\
\text { Structure: } \\
\text { Cutting tool: } \\
\text { Cutting speed: } \\
\text { Feed: } \\
\text { Cutting depth: } \\
\text { Working geometry: }\end{array}$}} & \multicolumn{3}{|c|}{ TiAl } \\
\hline & & & \multicolumn{3}{|c|}{ as-cast } \\
\hline & & & \multicolumn{3}{|c|}{$c B N, P C D$} \\
\hline & & & \multicolumn{3}{|c|}{100 and $200 \mathrm{~m} / \mathrm{min}$} \\
\hline & & & \multicolumn{3}{|c|}{$0.02 \mathrm{~mm} / \mathrm{rev}$} \\
\hline & & & \multirow{2}{*}{\multicolumn{3}{|c|}{$0.3 \mathrm{~mm}$}} \\
\hline & & & & & \\
\hline$\alpha_{0}$ & $\gamma_{0}$ & $\lambda_{S}$ & $\varepsilon_{r}$ & $\kappa_{\mathrm{r}}$ & $r_{\varepsilon}$ \\
\hline $6^{\circ}$ & $5^{\circ}$ & $0^{\circ}$ & $90^{\circ}$ & $75^{\circ}$ & $0.8 \mathrm{~mm}$ \\
\hline
\end{tabular}

Fig. 8 Total tool lives of different grades of cBN and PCD 
speed and feed rate are the most important influencing parameters. The used tools of uncoated cemented carbide reached the limit of their productivity at a cutting speed of $v_{\mathrm{c}}=60 \mathrm{~m} / \mathrm{min}$.

The use of superhard cutting materials offers higher cutting speeds of up to $v_{\mathrm{c}}=300 \mathrm{~m} / \mathrm{min}$. Above a cutting speed of $v_{\mathrm{c}}=100 \mathrm{~m} / \mathrm{min}$ no cracks and breakouts occur while turning as-cast and extruded TiAl. The low total tool life can be optimized by using adapted tool materials and cutting conditions.

The homogeneous extruded material structure causes lower cutting forces and greater surface qualities and tool lives. The influence of the material structure on the cutting temperatures during turning must be investigated as well as the influence of geometric parameters such as the rake angle. Tribological tests must be carried out to exert the influence of temperature on the different types of wear during machining of TiAl with geometrically defined cutting edges. Thus, further efforts are needed to research the economical cutting of this group of materials in order to determine suitable tools and machining conditions.

\section{REFERENCES}

1 Grabke, H. J. Oxidation of $\mathrm{NiAl}$ and FeAl. Intermetallics, 1999, 7, 1153-1158.

2 Noebe, R. D., Bowman, R. R., and Nathal, M. V. Physical and mechanical properties of the B2 compound NiAl. Int. Mater. Rev., 1993, 38(4), 193-232.

3 Smarsly, W., and Singheiser, L. Potential of intermetallics to replace superalloys for advanced operation conditions in gas turbines in Materials for advanced power engineering Part II (Eds D. Coutsouradis et al.), 1994, pp. 1731-1756 (Kluwer Academic Publishers, AZ Dordrecht).

4 Knippscheer, S. and Frommeyer, G. Structure and properties of intermetallic TiAl (Cr, Mo, Si) Alloys for lightweight engine parts. In Proceedings of the 9th World Conference on Titanium, St Petersburg, Vol. 1, (Central Research Institute of Structural Materials, St Petersburg, Russia) 2000, pp. 320-327.

5 Uhlmann, E., Schauerte, O. S., Brücher, M., and Herter, S. Tool wear during turning of titanium aluminide intermetallics. WGP Ann, 2001, VIII(2), 13-16.

6 Eckstein, M. and Smarsly, W. TiAl als Konstruktionswerkstoff und dessen spanende Bearbeitung am Beispiel hochbelasteter Komponenten in Fluggasturbinen, 1996, 1276, VDI-Berichte, 641-653.

7 Aust, E. and Niemann, H.-R. Machining of $\gamma$-TiAl. Advanced Engng. Mater., 1999, 1, 53-57.

8 Sauthoff, G. Intermetallic Alloys - materials development and prospects. Zeitschrift für Metallkunde, 1989, 80, 337-344.

9 Whittenberger, J. D., Noebe, R. D., and Garg, A. Elevated temperature compressive properties of $\mathrm{N}$-doped NiAl. Metall. Mater. Trans., 1996, A(27), 3170-3180.

10 Rablbauer, R. Mikrostrukturen und Eigenschaften quasibinärer eutektischer NiAl-Re und NiAl(Ti,Zr,Hf)B $B_{2}$-Legierungen für den Hochtemperatureinsatz. Dissertation, RWTH Aachen and MPIE Düsseldorf, 2005.

11 Clemens, H., Schretter, P., and Glatz, W. Mikrostruktur und Eigenschaften von g-TiAl-Basislegierungen. Praktische Metallographie, 1996, 33, 17-35.

\section{APPENDIX}

\section{Notation}

$a_{\mathrm{p}} \quad$ depth of cut (mm)

$A$ diameter after extrusion (mm)

$A_{0} \quad$ diameter before extrusion ( $\mathrm{mm}$ )

BDTT brittle-ductile transition temperature

$d \quad$ grain average main diameter $(\mu \mathrm{m})$

$D_{\mathrm{D}} \quad$ maximum turning diameter $(\mathrm{mm})$

$f \quad$ feed (mm)

$L_{\mathrm{D}} \quad$ maximum turning length ( $\mathrm{mm}$ )

$R_{\mathrm{z}} \quad$ average surface roughness $(\mu \mathrm{m})$

SEM scanning electron microscope

TEM transmission electron microscope

$T_{\mathrm{S}} \quad$ rake face temperature $\left({ }^{\circ} \mathrm{C}\right)$

$v_{\mathrm{c}} \quad$ cutting speed $(\mathrm{m} / \mathrm{min})$

vol \% per cent by volume

$V B \quad$ width of wear land (mm)

$\alpha_{\mathrm{o}} \quad$ orthogonal clearance angle $\left(^{\circ}\right)$

$\gamma_{\mathrm{o}} \quad$ orthogonal rake angle $\left(^{\circ}\right)$

$\kappa_{\mathrm{r}} \quad$ setting angle $\left({ }^{\circ}\right)$ 